\title{
Activity-Dependent Modulation of Glutamate Receptors by Polyamines
}

\author{
Derek Bowie, ${ }^{1}$ G. David Lange, ${ }^{2}$ and Mark L. Mayer ${ }^{1}$ \\ ${ }^{1}$ Laboratory of Cellular and Molecular Neurophysiology, National Institute of Child Health and Human Development, and \\ 2Instrumentation and Computers Section, National Institute of Neurological Disorders and Stroke, National Institutes of \\ Health, Bethesda, Maryland 20892
}

\begin{abstract}
The mechanisms by which polyamines block AMPA and kainate receptors are not well understood, but it has been generally assumed that they act as open-channel blockers. Consistent with this, voltage-jump relaxation analysis of GluR6 equilibrium responses to domoate could be well fit, assuming that spermine, spermidine, and philanthotoxin are weakly permeable open-channel blockers. Analysis of rate constants for binding and dissociation of polyamines indicated that the voltage dependence of block arose primarily from changes in $k_{\text {off }}$ rather than $k_{\text {on. }}$. Experiments with changes in $\mathrm{Na}$ concentration further indicate that the voltage dependence of polyamine block was governed by ion flux via open channels. However, responses to
\end{abstract}

Ionotropic Glu receptors (GluR) generated from AMPA receptor subunits respond to the transient presence of Glu in the synaptic cleft with rapid kinetics such that, at most synapses, AMPA receptors relay the signal mediating action potential initiation in the postsynaptic cell, whereas NMDA serves a modulatory role (Jonas and Spruston, 1994). Functional roles for kainate receptors at presynaptic (Chittajallu et al., 1996; RodriguezMoreno et al., 1997) and postsynaptic (Castillo et al., 1997; Vignes and Collingridge, 1997; Mulle et al., 1998) sites have also been identified in recent studies. RNA editing at the Q/R site of AMPA and kainate receptors (Sommer et al., 1991; Higuchi et al., 1993) regulates $\mathrm{Ca}^{2+}$ permeability (Jonas and Burnashev, 1995), anion versus cation selectivity (Burnashev et al., 1996), single-channel conductance (Howe, 1996; Swanson et al., 1996, 1997), and voltage-dependent block by cytoplasmic polyamines (Bowie and Mayer, 1995; Donevan and Rogawski, 1995; Isa et al., 1995; Kamboj et al., 1995; Koh et al., 1995). In each case, the positively charged Arg or neutral Gln residues at the Q/R site presumably influence the electrostatic environment of the pore differently and thus accounts for the distinct permeation properties of the $\mathrm{Q}$ and $\mathrm{R}$ forms.

There is increasing evidence for cell-specific expression of individual Glu receptor subtypes such that, in interneurons that lack GluR-B such as basket cells of the dentate gyrus, AMPA

\footnotetext{
Received June 5, 1998; revised July 21, 1998; accepted August 3, 1998.

We thank Dr. N. Burnashev for sharing results before publication, Drs. R. Bähring and V. Panchenko for discussion, Dr. M. Fleck for advice on flow pipe construction, and Drs. S. Traynelis, K. Swartz, and C.J. McBain for comments on previous drafts of this manuscript.

Correspondence should be addressed to Dr. M. L. Mayer, Building 49, Room 5A78, 49 Convent Drive, Bethesda MD 20892-4495.

Dr. Bowie's present address: Department of Pharmacology, Emory University, Rollins Research Center, 1510 Clifton Road, Atlanta, GA 30322-3090

Copyright (C) 1998 Society for Neuroscience $0270-6474 / 98 / 188175-11 \$ 05.00 / 0$
}

$1 \mathrm{msec}$ applications of L-Glu revealed slow voltage-dependent rise-times, suggesting that polyamines additionally bind to closed states. A kinetic model, which included closed-channel block, reproduced these observations but required that polyamines accelerate channel closure either through an allosteric mechanism or by emptying the pore of permeant ions. Simulations with this model reveal that polyamine block confers novel activity-dependent regulation on calcium-permeable AMPA and kainate receptor responses.

Key words: polyamines; glutamate receptors; plasticity; channel block; kinetic analysis; AMPA; kainate; ion channel block; ionic mechanism receptors have high $\mathrm{Ca}^{2+}$ permeability and rapid gating (Geiger et al., 1995, 1997) and hence should be subject to modulation by cytoplasmic polyamines. It has been proposed that the gating properties of synaptic receptors are pivotal in defining the functional roles fulfilled by interneurons in hippocampal network activity (Jefferys et al., 1996; Buzsáki and Chrobak, 1995). The physiological role fulfilled by polyamines and the possibility that polyamines could modulate the gating of Glu receptors has been neglected, despite their ubiquitous presence in all cells (Pegg, 1986) at cytoplasmic concentrations sufficient to produce strong block of AMPA and kainate receptors (Bowie and Mayer, 1995; Kamboj et al., 1995; Koh et al., 1995).

For inward rectifying potassium $\left(\mathrm{K}_{\mathrm{ir}}\right)$ channels, polyamine block has been proposed to stabilize the membrane potential at rest around the reversal potential $\left(V_{\text {rev }}\right)$ for $\mathrm{K}^{+}$ions (Hille, 1992; Nichols and Lopatin, 1997). Under conditions of excitation, depolarization increases block by polyamines of $\mathrm{K}_{\mathrm{ir}}$ channels, thus lowering the overall membrane conductance and reducing the metabolic expenditure of the cell for ionic homeostasis (Hille, 1992). A similar physiological role of polyamines for AMPA and kainate receptors would help to reduce influx of $\mathrm{Na}^{+}$and efflux of $\mathrm{K}^{+}$during action potential firing evoked by Glu-activated synaptic responses and could also reduce shunting of the action potential amplitude by EPSCs. We have shown previously that kainate receptors generated by GluR6(Q) and AMPA receptors generated by GluR-A both show birectifying responses in the presence of cytoplasmic polyamines, suggesting a common blocking mechanism (Bowie and Mayer, 1995). We now propose that polyamine block is bimodal in nature and attributable to both open- and closed-channel block mechanisms. A 12-state cyclic gating model was developed to satisfy our experimental observations. The model accounts for our observation that the rate of activation of responses to Glu is slowed in the presence of polyamines and 
reveals novel activity-dependent plasticity of AMPA and kainate receptor responses.

\section{MATERIALS AND METHODS}

Cell culture and expression of recombinant receptors. HEK 293 cells (CRL 1573; American Type Culture Collection, Manassas, VA) were maintained at a confluency of $70-80 \%$ in minimal essential medium with Earle's salts, $2 \mathrm{~mm}$ Gln, and $10 \%$ fetal bovine serum. Twenty-four hours after plating at low density $\left(2 \times 10^{4}\right.$ cells $\left./ \mathrm{ml}\right)$ onto the center of $35 \mathrm{~mm}$ Petri dishes, cells were transfected using the calcium phosphate technique; cotransfection with the cDNA for green fluorescent protein (S65T mutation) helped to identify transfected cells during experiments as described previously (Bowie and Mayer, 1995). Cells were washed with PBS 12-18 hr after transfection and used for electrophysiological recordings after another 24-48 hr. We used a cDNA clone for GluR6(Q) incorporated into a cytomegalovirus expression vector (a gift from Dr. P. Seeburg, Max Planck Institute, Heidelberg, Germany).

Recording conditions. Unless indicated, all experiments were performed in solutions with symmetrical $150 \mathrm{~mm} N$ a containing low concentrations of external divalents to minimize weak voltage-dependent block by $\mathrm{Ca}$ and $\mathrm{Mg}$ ions (Bowie and Mayer, 1996). The external solution was composed of $150 \mathrm{~mm} \mathrm{NaCl}, 5 \mathrm{~mm}$ HEPES, and $0.1 \mathrm{~mm}$ each of $\mathrm{CaCl}_{2}$ and $\mathrm{MgCl}_{2}$. The internal solution contained $120 \mathrm{~mm} \mathrm{NaCl}, 10 \mathrm{~mm} \mathrm{NaF}, 5 \mathrm{~mm}$ HEPES, $5 \mathrm{~mm} \mathrm{Na}_{4}$ BAPTA, and $0.5 \mathrm{mM} \mathrm{CaCl}_{2}$ to which spermine (Spm), spermidine (Spd) (Sigma), and philanthotoxin 343 (PhTX 343) (Research Biochemicals, Natick, MA) were added as required. In both cases, $\mathrm{pH}$ was adjusted to 7.3 , and osmolarity was adjusted to $295 \mathrm{mOsm}$ with sucrose. In experiments shown in Figure 4, the external solution was adjusted with $\mathrm{NaCl}$ to give $405 \mathrm{~mm}$ total Na content; the corresponding internal solution contained $375 \mathrm{~mm} \mathrm{NaCl}$. $\mathrm{Na}_{2} \mathrm{ATP}(10 \mathrm{~mm})$ was added to the internal solution in experiments performed in the absence of internal blocker to chelate endogenous polyamines present after patch excision (Bähring et al., 1997). In this case, $\mathrm{NaCl}$ content was reduced to $110 \mathrm{~mm}$ and $360 \mathrm{~mm} \mathrm{NaCl}$ to maintain the free $\mathrm{Na}$ concentration at 150 and 405 mM, respectively. The program BAD (Brooks and Storey, 1992) was used to calculate complex formation with ATP and hence the free $\mathrm{Na}^{+}$ concentration.

All recordings were made with an Axopatch-200A amplifier (Axon Instruments). Outside-out patches were excised from HEK 293 cells using fire-polished thin-walled borosilicate glass pipettes (2-5 M $\Omega$ ) coated with dental wax to reduce electrical noise. Series resistance (3-10 $\mathrm{M} \Omega$ ) was routinely compensated by $95 \%$. Current records were filtered (eight-pole Bessel filter) at $25 \mathrm{kHz}$, digitized at $50 \mathrm{kHz}$, and stored on a Macintosh IIfx or a Power Macintosh 7600/132 using a 16 bit analog-todigital converter (ITC-16; Instruteck Corp., Elmont, NY) under control of the program Synapse (Synergy Research, Silver Spring, MD). Two types of experiments were performed in this study. In the first, patches were treated with concanavalin-A $(0.1 \mathrm{mg} / \mathrm{ml}$ for $1-1.5 \mathrm{~min})$ to reduce desensitization, and the high-affinity GluR6 agonist domoate was applied via a stepper motor-based fast perfusion system (Vyklicky et al., 1990) at a saturating concentration $(50 \mu \mathrm{M})$ to promote a high probability of channel opening. The rate of onset of block (see Fig. $1 A, B$ ) was then studied using a series of voltage steps (5-15 msec duration) from a holding potential of $-100 \mathrm{mV}$, at which almost no block occurs, stepping to more depolarized potentials $(-85$ to $+125 \mathrm{mV}, 15 \mathrm{mV}$ increments) at which polyamine block is stronger. The rates of recovery from block (see Fig. $2 F$ ) were measured in patches held at $+40 \mathrm{mV}$, at which strong block occurs, stepping to a range of potentials which increased the rate of dissociation or permeation as appropriate $(-100$ to $+125 \mathrm{mV})$. Data obtained from each experimental paradigm were leak-subtracted. In the second experiment type, excised patches were placed near the interface of a four-bore glass flow pipe with control and $10 \mathrm{~mm}$ Glu-containing solutions fed by gravity. The solution was rapidly exchanged by displacement of the flow pipe using a piezoelectric stack (Physik Instrumente). The solution exchange rate was routinely determined at the end of each experiment by measuring the liquid junction potential between the solution containing $10 \mathrm{~mm}$ Glu and control solution in which total $\mathrm{Na}^{+}$-content was reduced by $5 \%$. Typically, 100-150 trials were averaged to obtain the junction currents. Data were discarded from patches in which the liquid junction currents exhibited slow rise times. Experiments were performed at room temperature $\left(24-26^{\circ} \mathrm{C}\right)$.

Kinetic analysis of voltage-jump relaxations. Model-independent analysis, such as exponential fitting and $10-90 \%$ rise times, were performed using the Synapse program (Synergy Research). The latency in channel opening observed in the presence of Spm was determined by aligning records with the piezoelectric stimulus artifact and subtracting the delay between the stimulus artifact and the rising phase of the junction current from the stimulus artifact and the rise of Glu-activated currents at -100 $\mathrm{mV}$. In all experiments, block by polyamines exhibited first order kinetics, suggesting that transitions between the two binding sites in a previously developed Eyring rate theory model can be reasonably well approximated by a single state (Bähring et al., 1997). To estimate block rate constants from voltage-jump experiments (see Fig. $2 A$ ), a function describing the time- and voltage-dependent nature of block for a single site model was defined and, as described below, appropriate algebraic substitutions were made to ensure that fit parameters converged on unique values. Code was written that permitted the simultaneous fitting of multiple current records at the various voltages tested $(-100$ to +125 $\mathrm{mV}$ ) with a nonlinear, steepest descent algorithm ("NonlinearFit") provided in the program Mathematica (Wolfram Research). The first 100 $\mu \mathrm{sec}$ of experimental data were masked to eliminate the rising phase of the voltage step, and current amplitudes were normalized to the response at $-100 \mathrm{mV}$. Fits of a typical experiment required 200-300 megabytes of random access memory and 40-60 min to allow convergence of the fitting procedure. For convenience, fits were semiautomated in batches on a $167 \mathrm{MHz}$ UltraSPARC Enterprise 3000 (Sun, Inc.).

The current relaxations observed with polyamines in voltage-jump experiments were fit by the blocking scheme shown below:

$$
X_{\text {Inside }} \stackrel{[B] k_{\text {on }}}{\underset{k_{\text {off }}}{\rightleftharpoons}} X_{\text {Site }} \stackrel{k_{\text {perm }}}{\rightleftharpoons} X_{\text {Outside }}
$$

where polyamines on the inside bind to a single site with a rate determined by the blocker concentration $[B]$ and $k_{\text {on }}$. Once bound, the blocker can leave the channel by either of two reactions: it may return to the inside $\left(k_{\text {off }}\right)$ or permeate through the channel to the external solution $\left(k_{\text {perm }}\right)$. Each rate constant is a function of voltage $(V)$ defined as:

$$
\begin{aligned}
k_{\text {on }} & =a \exp (V / b) \\
k_{\text {off }} & =c \exp (V / d) \\
k_{\text {perm }} & =e \exp (V / f)
\end{aligned}
$$

Current relaxations were fit by the function $I_{(\mathrm{t})}$, which describes membrane current at any time point and voltage:

$$
I_{(\mathrm{t})}=\left\{\left(I_{0}-I_{\infty}\right) \exp \left(-\left([B] k_{\text {sum }} t\right)\right)+I_{\infty}\right\}
$$

where $k_{\text {sum }}$ is the sum of all rate constants (Eqs. 1-3) and $t$ is time. Membrane current before blocker entry $\left(I_{0}\right)$ was defined as:

$$
I_{0}=\left(V-V_{\text {rev }}\right)\left\{G_{\text {min }}+\left(G_{0}-G_{\text {min }}\right) \exp \left(V / V_{\mathrm{c}}\right)\right\}
$$

where $V_{\text {rev }}$ is the reversal potential, $G_{0}$ is conductance at $0 \mathrm{mV}, G_{\min }$ is the minimal conductance (normalized value of 1 ), and $V_{\mathrm{c}}$ is a constant. Averaged values for $V_{\mathrm{rev}}, G_{0}$, and $V_{\mathrm{c}}$ were $-1.06 \pm 0.57,1.10 \pm 0.01$, and $51.1 \pm 0.10 \mathrm{mV}(n=57$ patches; mean \pm SEM $)$, respectively, and did not vary with blocker concentration. Membrane current at equilibrium block $\left(I_{\infty}\right)$ was defined as:

$$
I_{\infty}=\frac{I_{0}}{1+\frac{[\text { Blocker }]}{K_{\mathrm{d}}}}
$$

To obtain unique fits to Equation 4, the equilibrium dissociation constant $\left(K_{\mathrm{d}}\right)$ calculated from Equations 1-3 as:

$$
K_{\mathrm{d}}=\frac{\text { Sum of exit rates }}{\text { Binding rate }}
$$

was redefined to

$$
K_{\mathrm{d}}=g \exp (V / h)+j \exp (V / k)
$$

where

$$
g=\frac{c}{a} \text { and } j=\frac{e}{a}
$$


Table 1. Rate constants for open channel block by polyamines

\begin{tabular}{|c|c|c|c|c|c|c|}
\hline \multirow[b]{2}{*}{ [Blocker] $(\mu \mathrm{M})$} & \multicolumn{2}{|l|}{$k_{\text {on }}$} & \multicolumn{2}{|l|}{$k_{\text {off }}$} & \multicolumn{2}{|l|}{$k_{\text {perm }}$} \\
\hline & $\mathrm{a}\left(\mu \mathrm{M}^{-1} \sec ^{-1}\right)$ & $\mathrm{b}(\mathrm{mV})$ & $\mathrm{c}\left(\sec ^{-1}\right)$ & $\mathrm{d}(\mathrm{mV})$ & $\mathrm{e}\left(\sec ^{-1}\right)$ & $\mathrm{f}(\mathrm{mV})$ \\
\hline $\begin{array}{l}\text { Spermine }(5,10,20, \\
\quad \text { and } 30) n=19\end{array}$ & $48.5 \pm 1.7$ & $98.8 \pm 0.6$ & $132.3 \pm 13.2$ & $-18.1 \pm 0.9$ & $10.6 \pm 1.9$ & $19.5 \pm 1.0$ \\
\hline $\begin{array}{l}\text { Spermidine }(15,50, \\
\quad \text { and } 100) n=23\end{array}$ & $32.6 \pm 1.1$ & $100.6 \pm 0.2$ & $355.4 \pm 12.9$ & $-17.5 \pm 0.7$ & $39.8 \pm 3.3$ & $23.4 \pm 0.5$ \\
\hline $\operatorname{PhTX}(15,50$, and & & & & & & \\
\hline 100) $n=15$ & $14.1 \pm 1.2$ & $100.2 \pm 0.1$ & $199.6 \pm 16.0$ & $-19.0 \pm 0.6$ & $40.9 \pm 5.4$ & $100.2 \pm 0.1$ \\
\hline
\end{tabular}

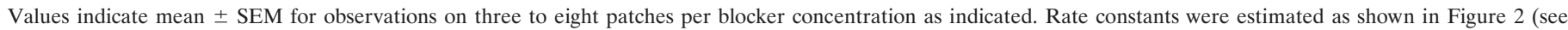
Materials and Methods, Eqs. 1-3).

$$
h=\frac{b-d}{b d} \text { and } k=\frac{b-f}{b f}
$$

Thus, $k_{\text {off }}$ and $k_{\text {perm }}$ can also be redefined accordingly:

$$
\begin{gathered}
k_{\text {off }}=a g \exp (V(b+h / b h)) \\
k_{\text {perm }}=a j \exp (V(b+k / b k))
\end{gathered}
$$

Definitions of $k_{\text {off }}$ and $k_{\text {perm }}$ (Eqs. 11 and 12) were substituted into $k_{\text {sum }}$ of Equation 4, and this form of the function with the redefined $K_{\mathrm{d}}$ (Eq. 8 ) were used to determine rate constants from fits to experimental data. Unless indicated otherwise, all values are presented as the mean \pm SEM in the text and figure legends.

Kinetic modeling of GluR6(Q) channel activity. The basic framework for the construction of a gating model for GluR6 was aided by previous studies investigating the kinetic behavior of this receptor (Heckmann et al., 1996; Traynelis and Wahl, 1997). Simulations were performed using code written in Mathematica assuming 1000 channels of conductance at $16 \mathrm{pS}$ (Traynelis and Wahl, 1997). Occupancy of each state was calculated from Q-matrices using the method of Colquhoun and Hawkes (1977) and Mathematica code provided by Dr. A. Roth (Max Planck Institute, Heidelberg, Germany), available at MathSource Electronic Library (http://www.mathsource.com). Numerical values assigned to rate constants for binding and gating steps gave a maximum open probability consistent with dose-response analysis (Traynelis and Wahl, 1997). Close attention was given to choosing values for channel closure $(\alpha)$ and the rate of entry $\left(d_{1}\right)$ into the double-liganded, desensitized state to match the decay rates of responses observed experimentally after 1 and $50 \mathrm{msec}$ pulses of $10 \mathrm{~mm}$ Glu at a range of membrane potentials $(-100$ to +125 $\mathrm{mV})$. Although single-channel analysis reveals substates for GluR6(Q) (Swanson et al., 1996), deactivation of responses to $1 \mathrm{msec}$ pulses of Glu was well fit by a single exponential function, justifying the use of a single open state. Experimentally observed decay rates were weakly voltagedependent in both cases and could be adequately modeled when $\alpha$ was assumed to be voltage-dependent (see Fig. $6 B$ ). The state diagram for the simple sequential open-channel-blocking scheme in Model 1 is shown below:

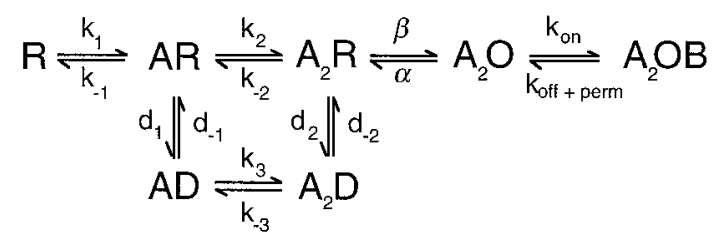

with rate constants as follows: $k_{1}=2 \times 10^{7} \mathrm{~mol}^{-1} \mathrm{sec}^{-1} ; k_{-1}=300$ $\mathrm{sec}^{-1} ; k_{2}=k_{3}=1 \times 10^{7} \mathrm{~mol}^{-1} \mathrm{sec}^{-1} ; k_{-2}=10^{5} \mathrm{sec}^{-1} ; d_{1}=100 \mathrm{sec}^{-1}$; $d_{-1}=1 \mathrm{sec}^{-1} ; d_{2}=1.39 \times 10^{4} \mathrm{sec}^{-1} ; d_{-2}=0.2 \mathrm{sec}^{-1} ; \beta=5000 \mathrm{sec}^{-1}$; $\alpha=324 \exp (-\mathrm{V} / 305) \mathrm{sec}^{-1}$. To satisfy the law of microscopic reversibility, $k_{-3}$ was set to $144 \mathrm{sec}^{-1}$. The numerical values for Spm block rate constants are summarized in Table 1. To simulate the gating of homomeric GluR-D (see Fig. 6), the channel closing rate was increased fivefold $\left(\alpha=1500 \exp (-V / 305) \mathrm{sec}^{-1}\right)$; in this case, current relaxations generated by $1 \mathrm{msec}$ applications of $10 \mathrm{~mm}$ L-Glu decayed with first order kinetics in the absence of polyamines (tau, $0.6 \mathrm{msec}$ at $-60 \mathrm{mV}$ ), similar to previously published experimental values (Lomeli et al., 1994). Simulations of trains were performed with desensitized states omitted from the model.

The state diagram of Model 2 for a mechanism with closed- and open-channel block is shown below:

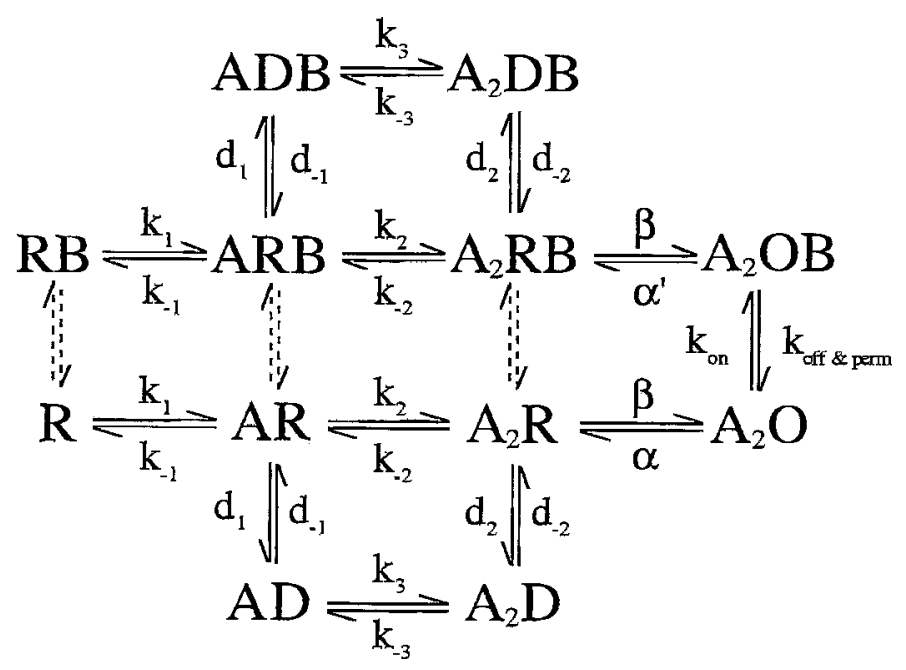

We assumed that Spm does not affect agonist binding or desensitization rates. Therefore, the numerical values assigned to these rate constants are the same as for Model 1. The closing rate constant $\left(\alpha^{\prime}\right)$ was twofold faster for open blocked channels to account for the experimentally observed faster rate of deactivation in the presence of Spm. In addition, before the first agonist application, all channels were assumed to be in the closed blocked state of the channel (RB). This satisfies the slow voltagedependent rise times observed experimentally in the presence of Spm, because channels first have to unblock before reaching the open state. We have no quantitative information describing the kinetics of closedchannel block and, therefore, simulations were performed omitting reactions between closed and closed blocked states. However, recent experiments indicate that the rate of polyamine block of closed AMPA receptors occurs on a time scale that would not significantly influence the simulations performed in the present study (Rozov et al., 1998).

\section{RESULTS}

\section{Rapid onset of open-channel block by polyamines}

Although it is known that the development and recovery of GluR block by polyamines is very rapid, previous studies with voltage jumps had failed to resolve the relaxations expected for openchannel block by Spm (Koh et al., 1995). To study the kinetics of block by polyamines, the membrane potential of outside-out patches containing GluR6(Q) channels was stepped in $15 \mathrm{mV}$ increments from $-100 \mathrm{mV}$ to $+125 \mathrm{mV}$ in the presence of the weakly desensitizing agonist domoate $(50 \mu \mathrm{M})$. Membrane cur- 
A $100 \mu \mathrm{M}$ PhTX

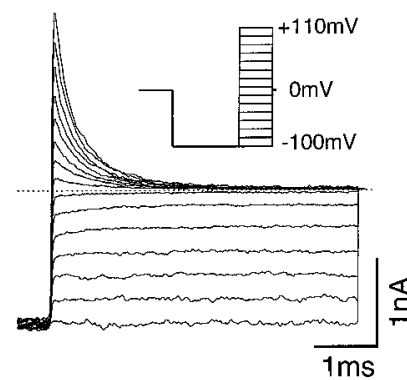

C

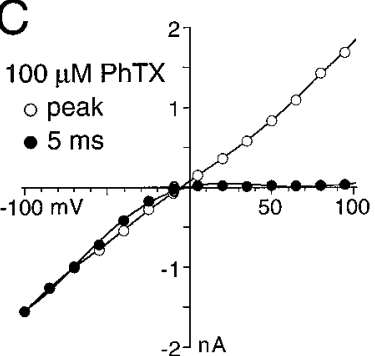

E Control $[A T P]_{i}$

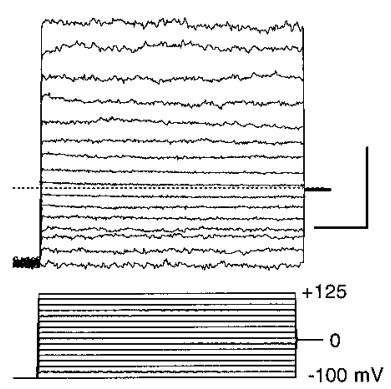

B $30 \mu \mathrm{M}$ Spermine

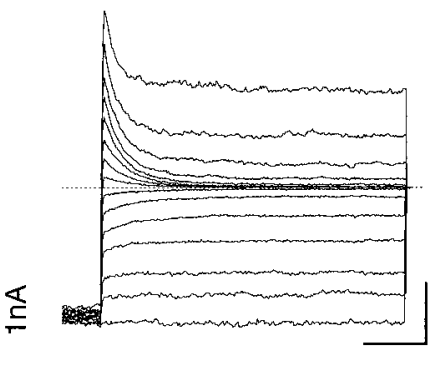

D

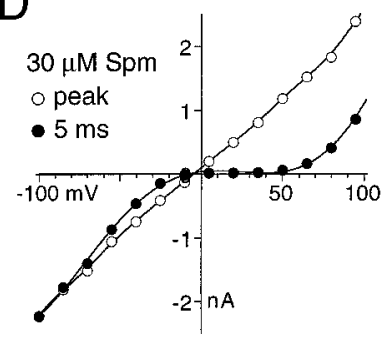

F

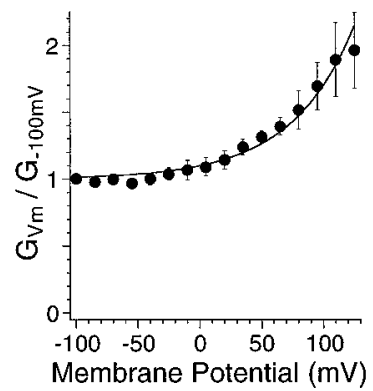

Figure 1. Time course of open-channel block by polyamines. $A$, GluR6(Q) responses recorded from an outside-out patch after voltage steps from -100 to $+125 \mathrm{mV}$ in $15 \mathrm{mV}$ increments with $50 \mu \mathrm{M}$ domoate and $100 \mu \mathrm{M}$ internal PhTX. $B$, Similar experiment on another patch with $30 \mu \mathrm{M}$ internal Spm. $C, D, I-V$ relationship for the responses shown in $A$ and $B$ measured at peak (open circles) and $5 \mathrm{msec}$ after depolarization (closed circles). E, In the absence of internal polyamines, GluR6(Q) responses to domoate did not show relaxations after voltage steps from -100 to $+125 \mathrm{mV}$. Dashed lines in $A, B$, and $E$ indicate zero current. $F$, $G-V$ plot for seven experiments similar to that shown in $E$ (mean $\pm \mathrm{SD}$ ) normalized to the conductance at $-100 \mathrm{mV}$. The continuous line through the data points predicts the voltage dependence of domoate responses in the absence of polyamines and was generated using Equation 5, with mean values for $G_{0}(1.10 \pm 0.01)$ and $V_{\mathrm{c}}(51.1 \pm 0.10 \mathrm{mV})$ obtained from kinetic analysis of responses in the presence of Spm, Spd, and $\operatorname{PhTX}(n=$ 57 patches; see Table 1 ), as shown in Figure $2 A$.

rents after depolarizing voltage steps showed well resolved relaxations, which decayed with first order kinetics when 15-100 $\mu \mathrm{M}$ $\operatorname{PhTX}(n=15)$ (Fig. 1A), 5-30 $\mu \mathrm{M} \mathrm{Spm}(n=19)$ (Fig. $1 B)$, or 15-100 $\mu \mathrm{M}$ Spd $(n=23$; data not shown) were added to the internal solution. $I-V$ relationships constructed for peak responses exhibited weak outward rectification (Fig. 1C,D), similar to that observed in the absence of polyamines (Figs. $1 E, F, 2 C$ ). In contrast, $I-V$ plots constructed $5 \mathrm{msec}$ after the onset of depolarization were strongly rectifying, consistent with previous analysis of equilibrium polyamine block (Bowie and Mayer, 1995; Bähring et al., 1997; Bähring and Mayer, 1998). In contrast to Spm and
Spd, which showed biphasic rectification attributable to relief of block with strong depolarization, outward currents remained fully blocked in the presence of $100 \mu \mathrm{M}$ PhTX, consistent with previous findings that the larger cross-sectional width of PhTX greatly slows progress through the ion-permeation pathway (Bähring et al., 1997; Bähring and Mayer, 1998). Because current relaxations were observed only when polyamines were added to the internal solution (Fig. $1 E$ ), our observations suggest that after voltage steps from $-100 \mathrm{mV}$, open channels begin to accumulate in a voltage-dependent blocked state and that the current decay observed in each case reflects the time course of polyamine block.

\section{Kinetic analysis of rate constants for polyamine block}

The kinetics of onset of block at each membrane potential were used to determine rate constants for binding, unbinding, and permeation of polyamines by fitting current relaxations with a single binding site reaction scheme for a permeant blocker (see experimental procedures in Materials and Methods). Figure $2 \mathrm{~A}$ shows a typical fit to experimental data, in this case, with $20 \mu \mathrm{M}$ internal Spm. Fits of similar quality in which the data points are fit well throughout the time course of the onset of block were also obtained with PhTX and Spd (data not shown). Estimates of rate constants were independent of blocker concentration; for example, fits for 5, 10, 20, and $30 \mu \mathrm{M}$ Spm gave estimates for $K_{\mathrm{d}(0 \mathrm{mV})}$ of $3.3 \pm 0.6(n=4), 4.1 \pm 1.7(n=4), 2.8 \pm 0.2(n=5)$, and $3.3 \pm$ $0.7(n=6) \mu \mathrm{M}$, respectively, where $K_{\mathrm{d}}$ was calculated from $\left(k_{\text {off }}+\right.$ $\left.k_{\text {perm }}\right) / k_{\text {on }}$. The sum of the rate constants for binding, dissociation, and permeation predicted well the experimentally observed kinetics of block at all membrane potentials tested when relaxations were fit by single exponential functions. Figure $2 B$ shows an example for $20 \mu \mathrm{M} \mathrm{Spm}$. As an additional test of the adequacy of the estimated rate constants for predicting polyamine block, we simulated $I-V$ relationships at different time points to permit comparison with experimental observations. $I-V$ plots in Figure $2 C$ show data from experiments performed in the absence of polyamines (open circles) or with $20 \mu \mathrm{M} \mathrm{Spm}$ at $100 \mu \mathrm{sec}$ and 5 msec after a depolarizing step from $-100 \mathrm{mV}$. Lines in Figure $2 C$ through the points are simulated $I-V$ plots generated using the rate constants for block by Spm (Table 1) and illustrate that the scheme accurately predicts current before entry of polyamines into the channel, as well as during the development of block. The voltage dependence of binding $\left(k_{\mathrm{on}}, e\right.$-fold per $\left.98.8 \mathrm{mV}\right)$, unbinding $\left(k_{\text {off }}, e\right.$-fold per $\left.-18.1 \mathrm{mV}\right)$, and permeation $\left(k_{\text {perm }}, e\right.$-fold per $19.5 \mathrm{mV}$ ) for Spm suggests that at membrane potentials below the threshold for initiation of action potentials the voltage dependence of block is almost entirely attributable to the unbinding rate, a feature also possessed by our previously published Eyring rate theory model, which contains an asymmetrical inner barrier (Bähring et al., 1997). Rate constants of binding and dissociation for both Spd and PhTX exhibited similar voltage dependencies to those for Spm, suggesting that the location of the binding site was probably the same for each blocker (Table 1).

Because the proposed mechanism of block displays first order kinetics, we would expect the binding rates for polyamines to be linearly dependent on concentration. To examine the effect of polyamine concentration on block rates, current relaxations with different Spm concentrations were compared at $+35 \mathrm{mV}$, because the magnitude of $k_{\text {on }}$ with respect to unbinding rates is greatest at this voltage (Fig. $2 B$ ). Figure $2 D$ shows that current relaxations decayed more rapidly with increasing Spm concentration, consistent with the prediction. Block rates determined from single exponential fits of similar data from multiple patches displayed a 


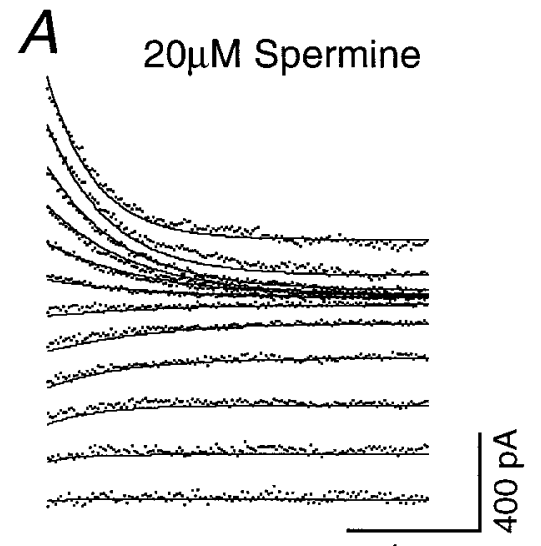

$1 \mathrm{~ms}$

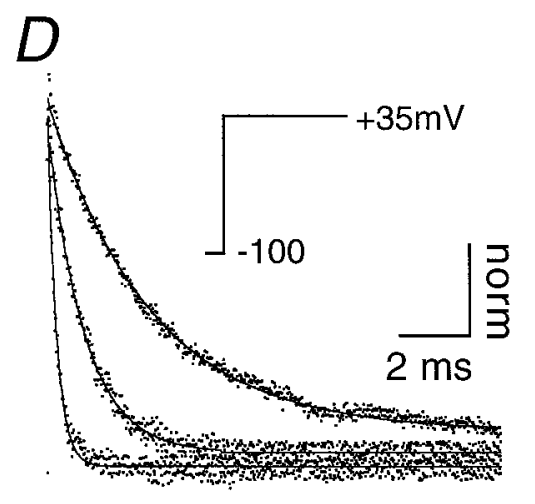

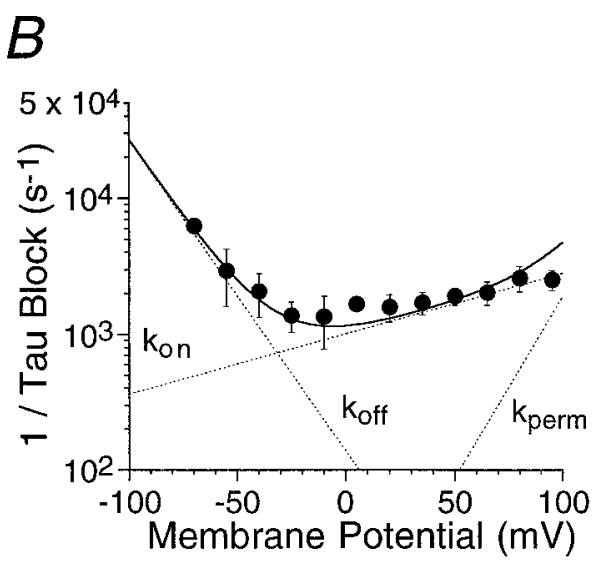
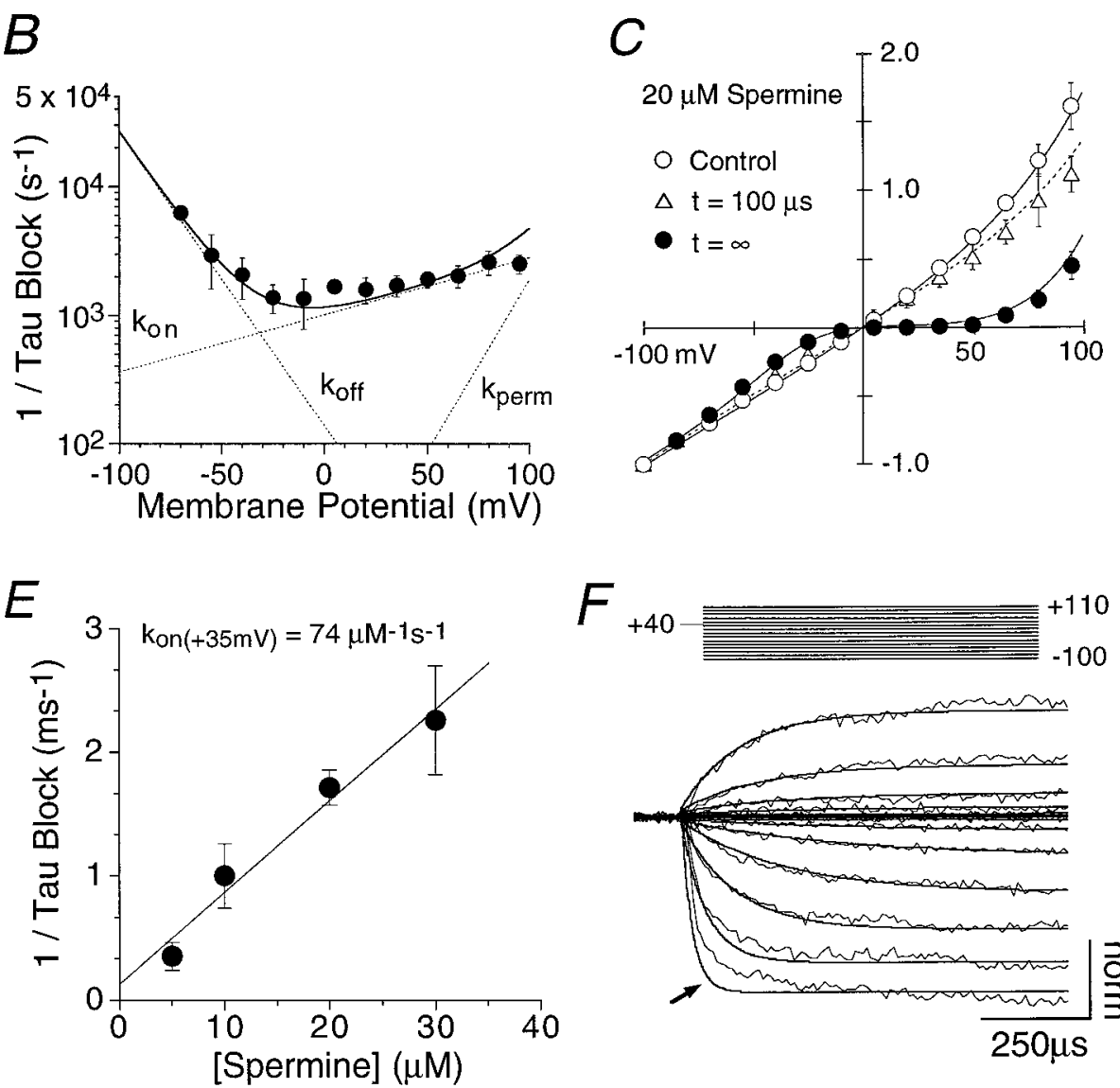
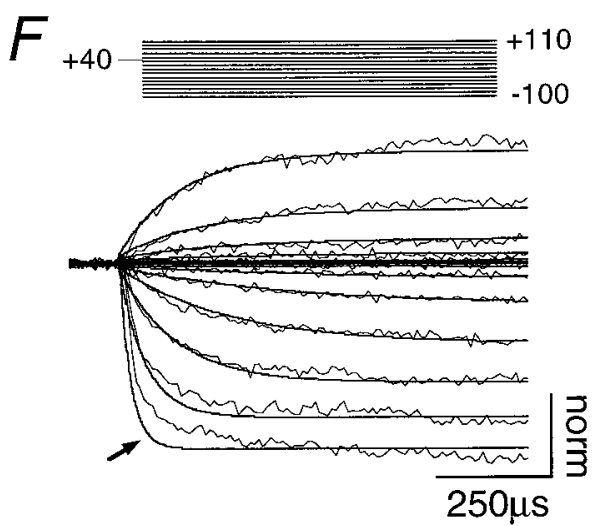

Figure 2. Fits of a sequential open-channel block model to polyamine responses. $A$, Current relaxations recorded with $50 \mu \mathrm{M}$ domoate and $20 \mu \mathrm{M}$ internal Spm after voltage steps from -100 to $+95 \mathrm{mV}$ in $15 \mathrm{mV}$ increments. Lines through the data points are fit by a single binding site reaction scheme for a permeant blocker (Eq. 4). $B$, Rate of onset of block observed at different voltages with $20 \mu \mathrm{M} \mathrm{Spm}(n=5$; mean \pm SD). Data points indicate the reciprocal of the time constant of single exponential fits to responses like those shown in $A$; solid lines through the data points are the sum of mean values for $k_{\text {on }}, k_{\text {off }}$, and $k_{\text {perm }}(n=57$ patches; see Table 1) estimated by fitting Equation 4 to responses like those shown in $A$. $C, I-V$ plots recorded either in the absence of blocker $(n=7)$ or with $20 \mu \mathrm{M} \mathrm{Spm}(n=5)$; in the latter case, responses were measured $100 \mu \mathrm{sec}$ and $5 \mathrm{msec}$ after the onset of depolarization. Lines through data points show the current predicted by Equation 4 using mean values from Table 1 at time 0 , before the onset of block, at $100 \mu \mathrm{sec}$ after depolarization and at equilibrium $(t=\infty)$. D. Relaxations observed with different Spm concentrations $(5,10$, and $30 \mu \mathrm{M})$ after voltage steps from -100 to $+35 \mathrm{mV}$. Responses are from different patches normalized to the amplitude of the fully unblocked response at $-100 \mathrm{mV}$; the rate of onset of block (solid line) was fit by a single exponential. $E$, Rate of onset of block at $+35 \mathrm{mV}$ for different concentrations of Spm reveals a linear relationship, consistent with an open-channel-blocking scheme. The solid line was fit by linear regression; the slope yields an estimate for $k_{\text {on }}$ at $+35 \mathrm{mV}$ of $7.4 \times 10^{7} \mathrm{~mol}^{-1} \mathrm{sec}^{-1}$, and the intercept was $132 \mathrm{sec}^{-1}$. Both values are in good agreement with predictions of $6.9 \times 10^{7} \mathrm{~mol}^{-1} \mathrm{sec}^{-1}$ and $83 \mathrm{sec}^{-1}$, respectively, calculated from values in Table 1 . F, Relaxations after voltage steps from $+40 \mathrm{mV}$ to potentials ranging from -100 to $+110 \mathrm{mV}$ with 30 $\mu \mathrm{M}$ internal Spm. Simulations (smooth line) using mean values for the rate constants for Spm block (Table 1) accurately predict the time course of the relaxations, except at -85 and $-100 \mathrm{mV}$, for which the reaction scheme predicts slightly faster reequilibration than observed experimentally (arrow).

linear relationship with Spm concentration, yielding an estimate for $k_{\text {on }}$ at $+35 \mathrm{mV}$ of $7.4 \times 10^{7} \mathrm{~mol}^{-1} \mathrm{sec}^{-1}$ (Fig. 2E), in excellent agreement with the value of $6.9 \times 10^{7} \mathrm{~mol}^{-1} \mathrm{sec}^{-1}$ predicted from values in Table 1 . These observations are all consistent with an open-channel-blocking scheme. The values of the rate constants estimated from fits to the data from voltagejump experiments are summarized in Table 1 . Note that the rate of binding $\left(k_{\text {on }}\right)$ of Spm was more than threefold faster than for PhTX (Table 1). PhTX, which is a bulky analog of Spd with a total charge of +3 , most likely needs to assume a particular orientation to enter the channel, reducing its effective binding rate. Similar to results obtained with Spm, the rate constants for $k_{\text {on }}, k_{\text {off }}$, and $k_{\text {perm }}$ for PhTX were independent of concentration of 15-100 $\mu \mathrm{M}$. In agreement with recent experimental observations (Bähring and Mayer, 1998), simulations of equilibrium block by low concentrations of PhTX showed saturation at strongly depolarized potentials because of the voltage dependence of $k_{\text {perm }}$ (Table 1), indicating that despite its large size PhTX is weakly permeant.

As a final evaluation of the adequacy of the fit parameters, responses evoked by voltage steps from $+40 \mathrm{mV}$ were used to compare predictions and experimental observations during reequilibration from blocked to unblocked states; this is in contrast to the previous analysis of responses to voltage steps from -100 $\mathrm{mV}$ (Fig. 2A), which reflect reequilibration from unblocked to blocked states. Figure $2 F$ shows relaxations observed with $30 \mu \mathrm{M}$ Spm after voltage steps from $+40 \mathrm{mV}$ to both hyperpolarized and depolarized potentials for which recovery from block occurs via unbinding and permeation of Spm, respectively. The smooth line in Figure $2 F$ shows predictions of the reaction scheme, which matches well experimental observations at all membrane potentials, except at $-85 \mathrm{mV}$ and $-100 \mathrm{mV}$ (Fig $2 F$, arrow) where reequilibration rates for the reaction scheme are slightly faster than observed experimentally. This could indicate the existence 
of a closed blocked state, the exit from which is slower than for open blocked channels at strongly negative potentials. Indeed, although the results shown in Figure 2 can be well explained by a simple model for open-channel block, as described below, clear evidence for closed blocked states was obtained from subsequent experiments indicating that the action of polyamines is more complex than previously realized.

\section{Analysis of responses to Glu reveals additional blocked states}

To determine whether polyamine block might influence activity at central synapses with unedited AMPA or kainate receptors (McBain and Dingledine, 1993; Isa et al., 1996), we developed a kinetic model for GluR6(Q) responses that matched well experimentally observed responses to brief applications of Glu in the absence of polyamines. The rate constants for polyamine block given in Table 1 were then used to simulate responses with $20 \mu \mathrm{M}$ internal Spm and $1 \mathrm{msec}$ pulses of a saturating concentration (10 $\mathrm{mm}$ ) of the neurotransmitter L-Glu, conditions typical for prototypic excitatory synapses (Clements et al., 1992). These simulated responses were then compared with experimental observations recorded using the same concentrations of Glu and Spm. Figure $3 A$ shows a typical control experiment in which Glu was applied for $1 \mathrm{msec}$ at different membrane potentials (range, -100 to +125 $\mathrm{mV}$ ) in the absence of internal polyamines. Because of the brief duration of the agonist pulse, the current decay reflects primarily the rate of channel closure. The rate of decay after removal of agonist was weakly voltage-dependent, decreasing $e$-fold per 300 $\mathrm{mV}$ depolarization (Fig. $3 E$ ). A six-state cyclic gating model with reaction rates chosen to simulate GluR6 responses described by Heckmann et al. (1996) was modified to match additional properties revealed by our experimental observations (Model 1) (see experimental procedures in Materials and Methods) and gave simulated responses that predicted well responses to Glu over a wide range of membrane potentials (Fig. $3 B$ ).

When block by Spm was included in simulations with Model 1, the current, particularly at positive potentials, decayed biexponentially with fast and slow components, reflecting the classical properties of a sequential open-channel-blocking scheme (Neher, 1983), similar to results obtained, for example, at the endplate (Colquhoun and Sheridan, 1981). The fast component of decay reflects the rate of open-channel block, whereas the slow component reflects the channel burst length, which is prolonged in the presence of open-channel blockers (Neher, 1983). In marked contrast to the predictions of Model 1, experimental responses evoked by $1 \mathrm{msec}$ pulses of $10 \mathrm{~mm}$ Glu in the presence of $20 \mu \mathrm{M}$ Spm decayed with first order kinetics without fast and slow components (Fig. 3D). Indeed, the rate of decay was faster than observed in the absence of blocker with no evidence of the slow voltage-dependent component predicted by simulations with 20 $\mu \mathrm{M}$ Spm (Fig. 3E). Consistent with the notion that an openchannel block mechanism alone is insufficient to account for the results shown in Figure $3 D$, conductance-voltage $(G-V)$ plots for peak responses determined from simulations with Model 1 for 20 $\mu \mathrm{M}$ Spm showed only weak attenuation of the peak response to Glu in contrast to the strong and voltage-dependent block observed experimentally (Fig. $3 F$ ). The model predicts weak attenuation of the peak response, because the rate of onset of block by $20 \mu \mathrm{M}$ Spm (Fig. 2) is slow compared with the rate of activation of GluR6(Q) by $10 \mathrm{~mm}$ Glu in the absence of polyamines. Together, these findings indicate that block had developed before
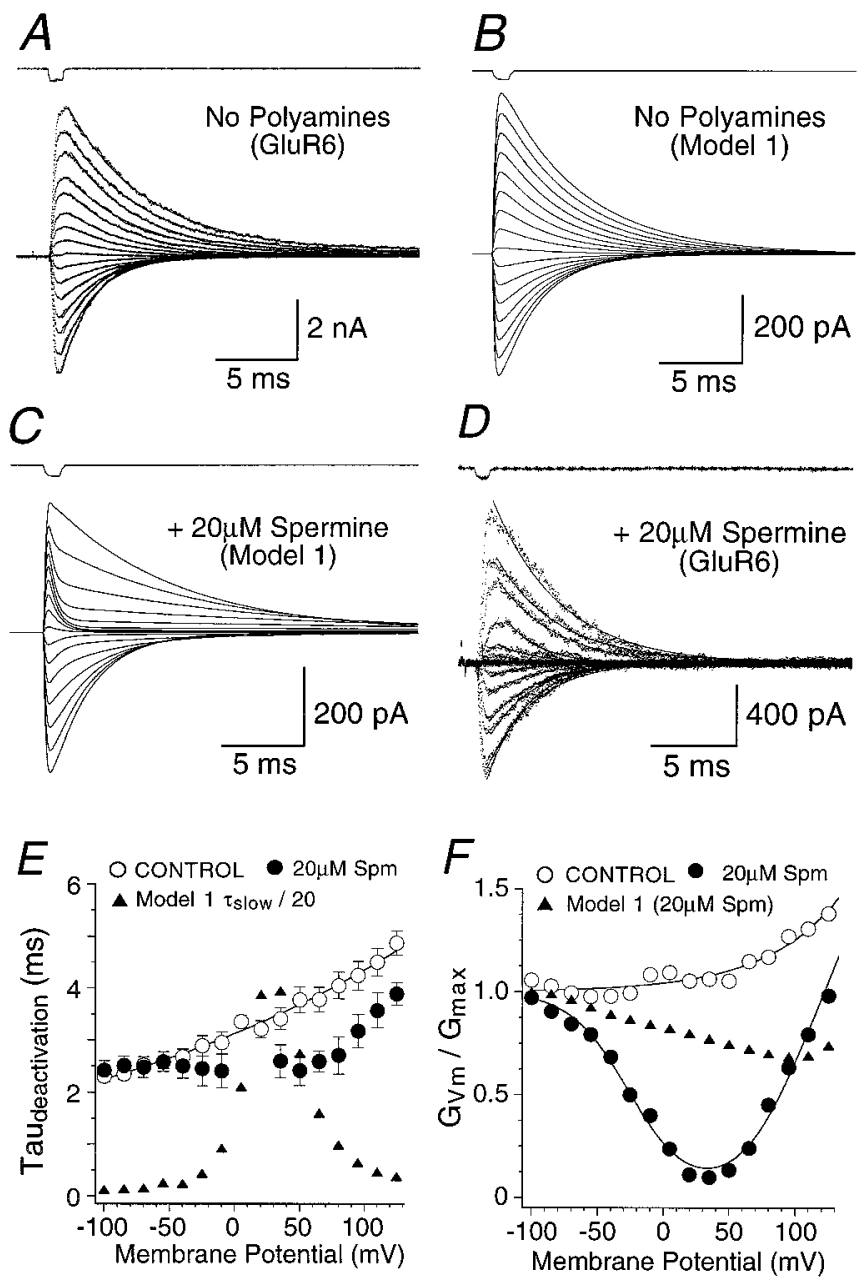

Figure 3. Sequential block fails to predict the kinetics of responses to Glu. $A$, Membrane currents evoked by $1 \mathrm{msec}$ applications of $10 \mathrm{~mm}$ Glu at various holding potentials ( -100 to $+125 \mathrm{mV}, 15 \mathrm{mV}$ increments) in the absence of internal polyamines; lines fit through the data points are single exponential functions. Top trace shows the junction current (1 $\mathrm{msec}$ ) recorded with an open patch electrode at the end of the experiment. $B$, Simulation of GluR6(Q) responses by Model 1 with the time course of agonist application adjusted to give exchange rates similar to those achieved in experiments (top trace). $C$, Simulation of GluR6(Q) responses by Model 1 but with $20 \mu \mathrm{M}$ internal Spm; note that at potentials producing strong block, the outward currents decay biexponentially. $D$, Experimentally recorded membrane currents evoked by 1 msec applications of $10 \mathrm{~mm}$ Glu in the presence of $20 \mu \mathrm{M}$ internal Spm. Responses to Glu decayed with first order kinetics at all voltages; lines fit through the data points are single exponential functions. $E$, Deactivation time constants as a function of voltage for control responses (open circles) $(n=7$; mean \pm SEM) and with $20 \mu \mathrm{M} \mathrm{Spm}$ ( filled circles) $(n=5$; mean \pm SEM). Deactivation was accelerated by $\mathrm{Spm}$ at membrane potentials more positive than $-50 \mathrm{mV}$. The line fit through control responses indicates an $e$-fold decrease in the time constant of deactivation per $303 \mathrm{mV}$ depolarization; filled triangles indicate the time constant of the slow component of deactivation ( $y$-axis scale is $1 / 20$ of measured values) estimated from double exponential fits to the simulated responses shown in $C . F, G-V$ plots for peak Glu responses observed in the presence ( $n=11$ patches) and absence ( $n=8$ patches) of $20 \mu \mathrm{M} \mathrm{Spm}$. Lines through the data points for $20 \mu \mathrm{M}$ Spm show fits based on Equation 8, corrected for the weak outward rectification of Glu responses observed in the absence of polyamines $\left(V_{\mathrm{c}}=56 \mathrm{mV}\right.$; Eq. 5). Filled triangles indicate peak conductance values determined from measurement of simulated responses with the same programs used for analysis of experimental data. 
activation of channel gating by Glu, suggesting that polyamines can bind to closed channels.

\section{Polyamine block slows the rise time of responses to Glu}

If channels were already blocked before activation by agonist and unblock after channels open, we would predict that the rising phase of responses to Glu would show biphasic voltage dependence, determined by the rate constants for binding and dissociation of polyamines to the open state (Fig. 2). To investigate this possibility, the rise times of Glu responses were analyzed in the presence or absence of blocker and compared as functions of membrane potential. We predicted that if Glu receptor channels were already blocked in the closed state, then the rise time after activation by agonist would be slowed and that this effect would be strongest at potentials in which polyamines bind with highest affinity. Thus, we would expect the rise times to become faster with either hyperpolarization or depolarization away from the potential for maximum block. Our experimental results fully confirmed this prediction.

In the absence of Spm, the 10-90\% rise times for responses to $10 \mathrm{~mm}$ Glu at $-100 \mathrm{mV}$ and $+50 \mathrm{mV}$ were similar, at $0.37 \pm 0.05$ and $0.44 \pm 0.05 \mathrm{msec}$, respectively $(n=9$ patches; mean $\pm \mathrm{SEM})$, and were essentially voltage-independent at all membrane potentials tested (Fig. $4 A, C$ ). When compared with open tip junction potentials recorded at the end of experiments, responses to Glu developed with a delay of $62 \pm 13 \mu \mathrm{sec}$, close to the limit of resolution determined by the solution exchange rate and the sample period for data acquisition $(n=9)$. In contrast, as shown in Figure 4, $B$ and $C$, Glu responses recorded with $20 \mu \mathrm{M}$ internal Spm showed voltage-dependent rise times that were much slower than control $(1.44 \pm 0.06 \mathrm{msec}$ at $+50 \mathrm{mV}$ and $0.53 \pm 0.04 \mathrm{msec}$ at $-100 \mathrm{mV}$ ) and a delay in channel opening after Glu application $(147 \pm 21 \mu \mathrm{sec}$ at $-100 \mathrm{mV} ; n=9)$. The rise times exhibited a bell-shaped voltage dependence (Fig. $4 C$ ), with the slowest responses recorded at $+20 \mathrm{mV}$ (rise time, $1.67 \pm 0.18 \mathrm{msec}$ ).

The slow voltage-dependent rise time of responses to Glu is consistent with our proposal that Spm can access its binding site when channels are closed, because the activation kinetics would then reflect reequilibration of the binding of blocker with the open state after channel activation by agonist (Fig. 2F). To further test this hypothesis, we examined the effect on Glu response rise times of lowering the affinity of the blocker for the open state, because in this scenario, the blocker would reside for a shorter period on its binding site and thus rise times should become faster. To achieve this, responses to $10 \mathrm{~mm}$ Glu in the presence of $20 \mu \mathrm{M}$ Spm were recorded in high permeant ion concentrations (symmetrical $405 \mathrm{~mm} \mathrm{Na}$ ). We have shown previously that polyamine affinity is strongly influenced by asymmetrical changes in either internal or external permeant ion concentration (Bähring et al., 1997). However, the shifts in $V_{\text {rev }}$ observed in asymmetrical ion gradients did not permit a distinction to be made between changes in ion flux or the membrane potential as the mechanism underlying shifts in the voltage dependence of polyamine block. Consistent with our previous finding that equilibrium block of responses to domoate was reduced on increasing $[\mathrm{Na}]_{\mathrm{o}}$, block of Glu responses by Spm was reduced in symmetrical solutions of $405 \mathrm{~mm} \mathrm{Na}\left(K_{\mathrm{d}(0 \mathrm{mV})}=31.6 \pm 3.5 \mu \mathrm{M} ; n=3\right)$ when compared with results for symmetrical $150 \mathrm{mM} \mathrm{Na}\left(K_{\mathrm{d}(0 \mathrm{mV})}=\right.$ $7.9 \pm 1.27 \mu \mathrm{M} ; n=8$ ), suggesting that block is governed primarily by ion flux via the channel and not membrane potential per se (Fig. 4D). Fits of the sum of two Boltzman functions showed that

\section{$A$ GluR6 No Polyamines}

$B$ GluR6 $20 \mu \mathrm{M}$ Spermine
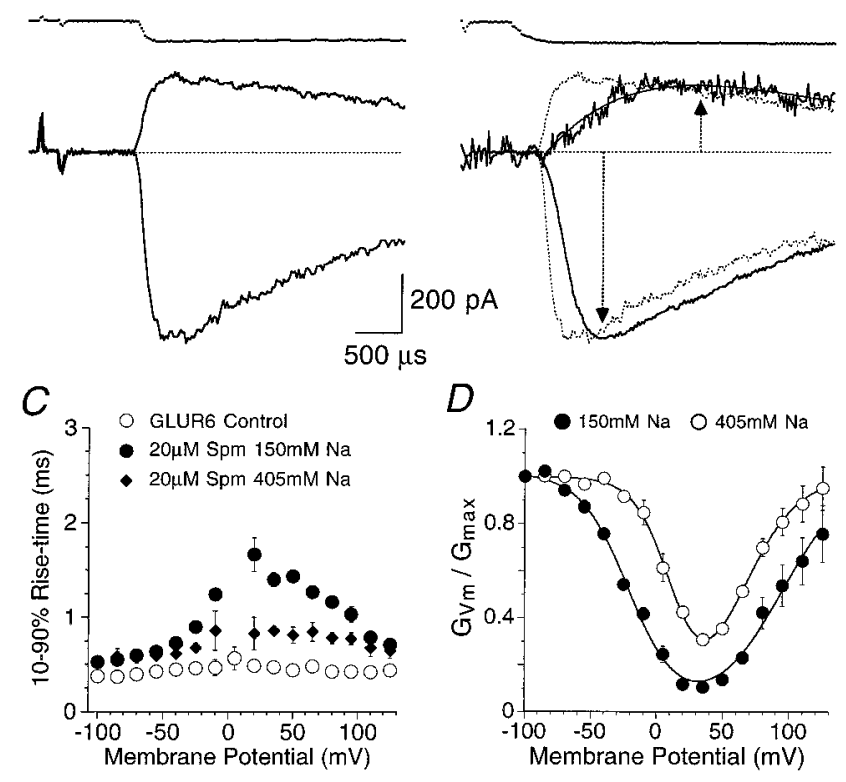

Figure 4. GluR6 activation kinetics are slowed in the presence of Spm. $A$, Control responses evoked by $50 \mathrm{msec}$ applications of $10 \mathrm{~mm}$ Glu at -100 and $+50 \mathrm{mV}$ and the open tip junction current for this experiment (top trace). The $10-90 \%$ rise times of the Glu responses (240 and 300 $\mu \mathrm{sec}$ ) were similar at -100 and $+50 \mathrm{mV}$. $B$, In the presence of $20 \mu \mathrm{M} \mathrm{Spm}$, responses to $10 \mathrm{~mm}$ Glu exhibited much slower and voltage-dependent $10-90 \%$ rise times of 420 and $940 \mu \mathrm{sec}$ at -100 and $+50 \mathrm{mV}$, respectively. The responses shown are an average of 11 trials and are scaled to match the amplitude of the control responses shown in $A$ (dotted lines). Scale bar: $175 \mathrm{pA}$ at $-100 ; 44 \mathrm{pA}$ at $+50 \mathrm{mV}$. Arrows indicate the time of the peak response, which at $+50 \mathrm{mV}$ was estimated by fitting a seventh order polynomial to the rising and falling phases (solid line); in $A$ and $B$, dashed lines indicate zero current. $C$, In the absence of Spm, $10-90 \%$ rise times for control responses to Glu were voltage-insensitive for both symmetrical $150 \mathrm{~mm} \mathrm{Na}$ (open circles) and symmetrical $405 \mathrm{~mm} \mathrm{Na}$ (data not shown). With $20 \mu \mathrm{M} \mathrm{Spm}$, rise times showed biphasic voltage dependence for $150 \mathrm{~mm} \mathrm{Na}$ ( filled circles) with weaker voltage dependence for $405 \mathrm{~mm} \mathrm{Na}$ ( filled diamonds). $D, G-V$ plots for peak Glu responses in symmetrical $150 \mathrm{~mm} \mathrm{Na}$ (filled circles) and symmetrical $405 \mathrm{~mm} \mathrm{Na}$ (open circles). Fits of $G-V$ plots with a single binding site reaction scheme (Eq. 4) reveals that Spm affinity is fourfold higher in $150 \mathrm{~mm}$ Na than in 405 mM Na. $G-V$ plots were corrected for the weak outward rectification observed in the absence of polyamines (Fig. $3 F$ ).

the voltage dependence of onset $(150 \mathrm{~mm} \mathrm{Na}, e$-fold per $-18.3 \pm$ $1.3 \mathrm{mV} ; 405 \mathrm{~mm} \mathrm{Na}, e$-fold per $-16.8 \pm 0.8 \mathrm{mV})$ and relief $(150$ $\mathrm{mm} \mathrm{Na}, e$-fold per $22.4 \pm 2.3 \mathrm{mV} ; 405 \mathrm{~mm} \mathrm{Na}, e$-fold per $21.3 \pm$ $7.6 \mathrm{mV}$ ) from block was almost identical in each case, suggesting that although the affinity of the blocker has changed, the location of the binding site within the membrane electric field is unaltered (see Eq. 8) (Fig. 4D). Glu response rise times in symmetrical 405 $\mathrm{mm} \mathrm{Na}$ with $20 \mu \mathrm{M} \mathrm{Spm}(0.83 \pm 0.17 \mathrm{msec} ; n=3$ at $+20 \mathrm{mV})$ were, as predicted, faster than observed with $150 \mathrm{~mm} \mathrm{Na}$ and 20 $\mu \mathrm{M}$ Spm $(1.67 \pm 0.18 \mathrm{msec})$, suggesting that the slow kinetics of the rising phase of the Glu response with Spm was attributable to reequilibration of the binding of blocker with the open state of the channel (Fig. 4C). In contrast, the delay in channel opening observed with $20 \mu \mathrm{M}$ Spm in symmetrical $405 \mathrm{~mm} \mathrm{Na}(290 \pm 34$ $\mu \mathrm{sec} ; n=4)$ remained slower than in the absence of polyamines (56 $\pm 29 \mu \mathrm{sec} ; n=4)$, suggesting that the molecular mechanisms responsible for the delay in channel activation are probably separate from those affecting the rise times of responses to Glu. In view of the difficulty in accurately resolving small differences in 
Figure 5. Voltage jumps reveal transitions between open and closed blocked states. $A$, Depolarizing steps to $+50 \mathrm{mV}$ were applied before or during the rising and falling phase (time increment, $500 \mu \mathrm{sec}$ ) of responses evoked by $50 \mathrm{msec}$ applications of $10 \mathrm{~mm}$ Glu at $-100 \mathrm{mV}$. When the depolarizing step preceded the application of Glu, the response at $+50 \mathrm{mV}$ showed strong block. In contrast, the envelope of the instantaneous currents evoked by depolarizing steps during the response to Glu matched well the amplitude of the response predicted for fully unblocked channels (open circles); this was estimated by averaging responses at $-100 \mathrm{mV}$ and correcting for the change in driving force and the weak outward rectification observed in the absence of polyamines (Fig. $3 F$ ). Note that the instantaneous currents evoked by steps from -100 to +50 $\mathrm{mV}$ at first overshoot the response observed when Glu was applied at $+50 \mathrm{mV}$ but then decay with double-exponential kinetics faster than the response at $-100 \mathrm{mV}$, as expected for onset of open-channel block (Fig. $3 C$ ). $B$, Same experimental paradigm as in $A$ but in the absence of polyamines. Note that the amplitude of the response recorded when the depolarizing step to $+50 \mathrm{mV}$ preceded the application of Glu matched well both the envelope of the instantaneous currents recorded on depolarization from -100 to $+50 \mathrm{mV}$, as well as the amplitude and time course of the response at $-100 \mathrm{mV}$ scaled for the change in driving force (open circles). $C$, Responses to $10 \mathrm{~mm}$ Glu (50 msec duration) at +50 and $-100 \mathrm{mV}$ were recorded immediately after steps to prepulse potentials between -100 to $+50 \mathrm{mV}(15$ $\mathrm{mV}$ increments, $200 \mathrm{msec}$ duration); the amplitude of individual responses did not vary with prepulse potential. Solid lines show the average of the responses at -100 and $+50 \mathrm{mV}$. In $A-C$, open tip junction potentials indicate the time of application of Glu. $D$, Similar analysis of results from four and eight patches, as indicated, confirm that the prepulse potential did not affect the amplitude of responses to Glu.

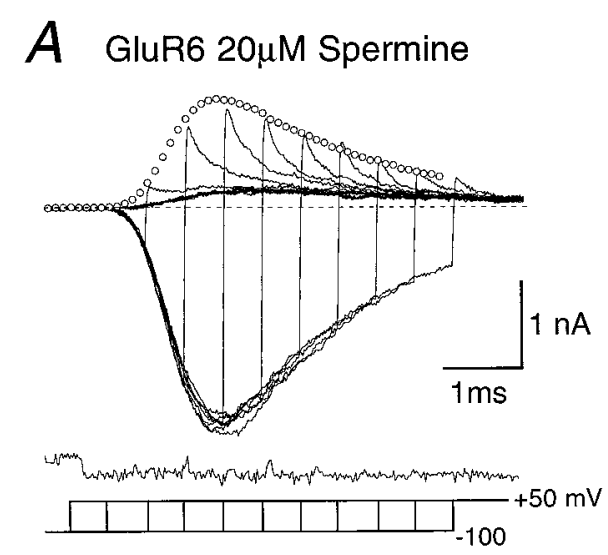

$B$ GluR6 No Polyamines
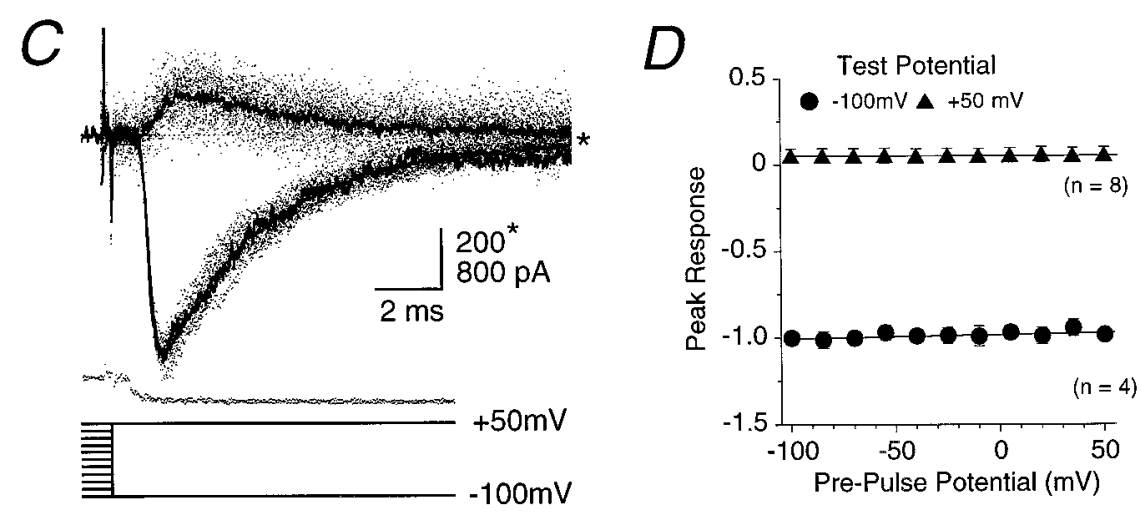

response latency, we have not investigated further the underlying mechanisms of this effect.

\section{Ion flux-dependent transitions between open and closed blocked states}

To explore further the conditions that influence transitions between open-channel block by Spm on the one hand (Figs. 1, 2) and closed-channel block on the other (Figs. 3, 4), we examined the effect of changing the membrane potential on responses to 10 mм Glu (50 msec duration) when channels were either open or closed (Fig. 5). Glu responses with $20 \mu \mathrm{M}$ Spm were recorded at $+50 \mathrm{mV}$, at which strong block occurs, and at $-100 \mathrm{mV}$, at which blocker affinity is low and thus relief of block is fast (Fig. $2 F$ ). The membrane potential was then stepped from -100 to $+50 \mathrm{mV}$ at various times preceding and during the rising and falling phase of the response to Glu. Figure 5, $A$ and $B$, illustrates typical examples of this experiment in the presence and absence of $20 \mu \mathrm{M}$ Spm, respectively. The response profile in the presence of $20 \mu \mathrm{M}$ Spm was strongly influenced by the time at which the step from $-100 \mathrm{mV}$ to $+50 \mathrm{mV}$ occurred (Fig. $5 A$ ). When the step to +50 $\mathrm{mV}$ preceded the application of agonist by 250 or $500 \mu \mathrm{sec}$, the peak response to Glu, when corrected for the change in driving force, was greatly reduced in amplitude $(7.2 \pm 1.2 \%$ of responses at $-100 \mathrm{mV} ; n=10)$ and showed a slow rise time $(10-90 \%$, $1.34 \pm 0.19 \mathrm{msec}$ at $+50 \mathrm{mV})$; these features are anticipated from the closed-channel block mechanism suggested by the experiments shown in Figures 3 and 4. In contrast, when the step from -100 to $+50 \mathrm{mV}$ occurred when channels were open, during either the rising or falling phase of the response to Glu, the instantaneous response at $+50 \mathrm{mV}$ showed almost no sign of block. For example, when corrected for the change in driving force at the peak of the Glu response, the amplitude at $+50 \mathrm{mV}$ was $98.5 \pm 4.1 \%$ of that at $-100 \mathrm{mV}(n=7)$.

In the presence of Spm, the large instantaneous outward currents evoked by steps from -100 to $+50 \mathrm{mV}$ decayed much faster than could be accounted for by the rate of onset of desensitization at $+50 \mathrm{mV}$ observed in the absence of polyamines (Fig. 5) and most likely reflects onset of open-channel block by Spm. Because the rate of onset of open-channel block is predicted to depend on Spm concentration, we compared the kinetics of such responses with 20 and $60 \mu \mathrm{M} \mathrm{Spm}$. In both cases, the current observed at $+50 \mathrm{mV}$ after voltage steps from $-100 \mathrm{mV}$ at the peak of the Glu response decayed biexponentially but with faster kinetics for 60 versus $20 \mu \mathrm{M} \mathrm{Spm}$. The fast component of block was threefold more rapid for $60 \mu \mathrm{M} \mathrm{Spm} \mathrm{(tau,} 0.14 \pm 0.07 \mathrm{msec} ; n=4$ ) 
compared with measurements with $20 \mu \mathrm{M}$ Spm (tau, $0.38 \pm 0.04$ msec; $n=7$ ), as anticipated from an open-channel block mechanism. The slower component of decay was also faster with $60 \mu \mathrm{M}$ Spm (tau, $0.84 \pm 0.59 \mathrm{msec} ; 38.7 \pm 8.9 \%$ ) compared with responses with $20 \mu \mathrm{M}$ Spm (tau, $3.2 \pm 0.35 \mathrm{msec}$; $41.7 \pm 4.6 \%$ ), and in both cases, the onset of block was faster than the rate of onset of desensitization of control responses with no polyamines (tau, $4.58 \pm 0.65 \mathrm{msec} ; n=5$ ) (Fig. $5 B$ ). The slower component of decay with polyamines observed in these experiments most likely reflects a combination of the burst length of open blocked channels and the onset of desensitization. Our observation that the slow component of decay recorded with polyamines occurs faster than the onset of desensitization and is much faster than predicted for a sequential open-channel block mechanism (Fig. 3C) most likely reflects truncation of the burst length attributable to entry of open blocked channels into closed blocked states. Together, our observations suggest that block of GluR6(Q) channels by internal polyamines is strongly activity-dependent.

To test whether occupancy of the closed blocked state by Spm is sensitive to the membrane potential, responses to $10 \mathrm{~mm}$ Glu were examined at $-100(n=4)$ and $+50 \mathrm{mV}(n=8)$ after prepulses over a range of membrane potentials previously shown to produce large changes in polyamine block when channels are open. In contrast, we found that when channels were closed the response amplitude was unaffected by the prepulse potential, with steps of $200 \mathrm{msec}$ duration (Fig. $5 C, D$ ); in preliminary experiments, similar results were obtained with prepulses of $2 \mathrm{sec}$ duration $(n=2)$.

\section{DISCUSSION}

\section{A kinetic model for bimodal block by polyamines}

Based on our experimental observations, we developed a kinetic model with open and closed blocked states (Model 2) (see experimental procedures in Materials and Methods). The model was based on simulations that predicted well control responses to Glu in the absence of polyamines (Model 1) but included additional closed blocked states. The model was tested by its ability to predict both the voltage dependence of the peak conductance and accelerated rate of decay of responses to $1 \mathrm{msec}$ applications of Glu (Fig. 3), as well as the biphasic voltage dependence of the rise time of Glu responses (Fig. 4). These key predictions of the model are summarized in Figure 6. In the presence of Spm, the voltagedependent rise time of responses to $10 \mathrm{~mm}$ Glu observed experimentally was well achieved by Model 2, confirming that equilibration of the binding of Spm with the open state during the rising phase of the response to Glu was sufficient to account for this effect (Fig. 6A). The model, however, did not predict fully the delay in channel activation observed experimentally (Fig. $4 B$ ), implying that Spm most likely stabilizes some of the closed states of the receptor; without additional information that would be difficult to obtain experimentally, there is no justification for incorporating additional closed states into the model or for altering the rate constants for binding of agonist and polyamines to closed states to increase their occupancy. The accelerated rate of deactivation observed in the presence of Spm (Fig. 3E) was achieved in the model by increasing the channel closing rate twofold for Spm-blocked channels (Fig. 6B). Although the molecular mechanism responsible for destabilization of the open state is not yet understood, such effects are typical of the action of many trapped channel blockers (Blanpied et al., 1997). One attractive possibility would be that because of their large size, polyamine molecules may exclude permeant cations from the
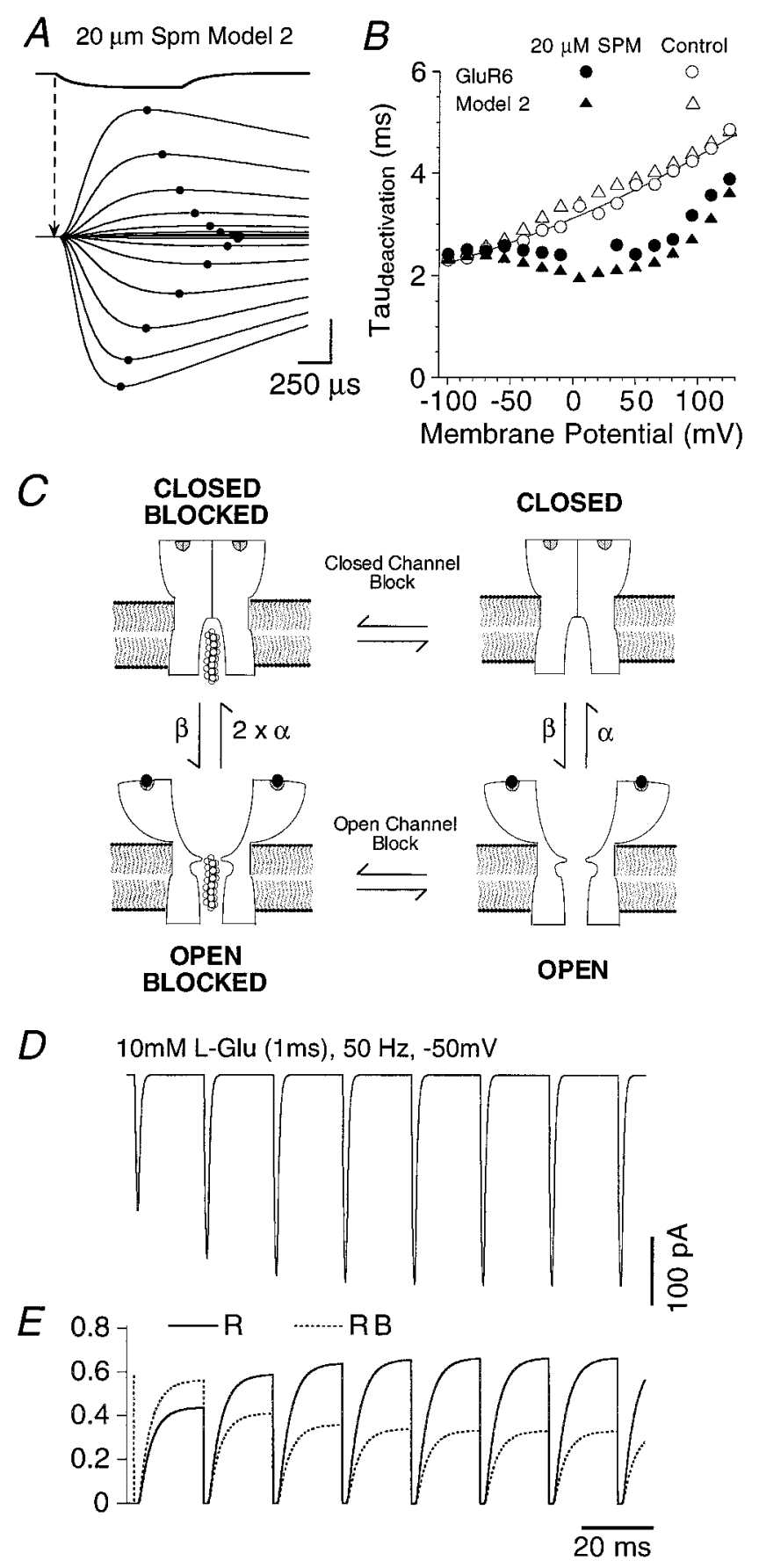

Figure 6. Modulation of responses to Glu by a bimodal blocking scheme. $A$, Simulation of responses to $1 \mathrm{msec}$ applications of $10 \mathrm{~mm}$ Glu, as shown in Figure $3 D$ but with Model 2. Consistent with experimental observations (Fig. 4), the peak response shows strong rectification, and the rise times show a bell-shaped voltage dependence; the time of occurrence of the peak response is indicated by filled circles. $B$, Simulation of the voltage dependence of deactivation of responses to $1 \mathrm{msec}$ applications of Glu ( filled triangles) agrees well with experimental observations ( filled circles) when the rate of channel closure is increased twofold for Spm-blocked channels. $C$, Schematic diagram for Model 2 indicating cycling between open and closed blocked states. $D, E$, Simulations showing facilitation of responses to $50 \mathrm{~Hz}$ trains of $1 \mathrm{msec}$ applications of $10 \mathrm{mM}$ Glu with $20 \mu \mathrm{M}$ Spm using rate constants adjusted to produce control responses like those for GluR-D (Lomeli et al., 1994). Traces in $E$ show occupancy of the closed $(R)$ and closed blocked $(R B)$ states of Model 2 during facilitation of responses to L-Glu; note the progressive decrease in occupancy of closed blocked states during successive responses to Glu. 
pore, with consequent effects on channel-closing kinetics similar to the effect of use-dependent blockers on $\mathrm{K}^{+}$-channels (Baukrowitz and Yellen, 1996).

\section{Binding of polyamines to closed GluR channels}

The recent elucidation of $\mathrm{K}^{+}$-channel structure from Streptomyces lividans (Doyle et al., 1998) offers a possible explanation to account for our observation that the occupancy of closed blocked states by polyamines was not detectably altered by membrane potential within the limit of resolution of our experimental protocols, whereas ion flux through the pore rapidly relieves polyamine block (Fig. 5). A diagram illustrating the key features of the proposed model is shown in Figure $6 C$ and requires that polyamines bind to a water-filled internal vestibule accessible in the closed state. This avoids the difficulty that the local potential around a charged molecule, such as Spm, would be large in a region of low dielectric constant, such as a narrow channel pore in a membrane. However, if the narrow pore is replaced by a larger cavity that accommodates polarizable water molecules, as proposed from $\mathrm{K}^{+}$-channel structure (Doyle et al., 1998), polyamines will be shielded and experience less of the potential drop across the membrane. The structure of the pore region in Glu receptors is unknown, but data from accessibility experiments using Cyssubstituted residues on NMDA (Kuner et al., 1996) and AMPA receptors (Kuner et al., 1997) indicate that the M2 segment forms a channel-lining hairpin loop accessible from the cytoplasmic side of the channel. The inverted orientation of the pore loop in Glu receptors relative to that in potassium channels would generate a tepee, with an external gate and internal selectivity filter surrounding a central hydrophobic cavity. Although it is premature to speculate on the precise orientation of the structural elements in Glu receptor pores, it is likely that the binding site with which polyamines interact during permeation would become fully accessible only after channel activation and that movement of polyamines into the blocking site after channel opening would precede and thus prevent measurable ion flux.

The blocking mechanisms that we propose underlie the action of Spm are summarized schematically in Figure $6 C$, which outlines the cyclic nature of the proposed scheme. Before receptor activation, cytoplasmic polyamines reside in a water-filled cavity that is accessible to the cytoplasm in the closed conformation and represents the closed blocked state. When the receptor binds Glu, the conformational steps associated with channel activation expose a polyamine binding site within the membrane electric field. The rate of binding and dissociation of Spm from the open state of the channel underlies the voltage dependence of the rise time of responses to Glu. Our results suggest that this process is governed to a large extent by ion flux via the channel rather than membrane potential per se. Such a model helps to explain the strong flux dependence of polyamine unblock (Fig. 5) and our previous observation that at equilibrium the voltage dependence of GluR6(Q) responses to domoate shows strong coupling to permeant ion concentrations (Bähring et al., 1997).

\section{Physiological consequences of polyamine block}

The rate of decay of the response to $1 \mathrm{msec}$ applications of L-Glu and presumably the rate of decay of EPSCs at synapses with polyamine-sensitive Glu receptors found in some interneurons (Geiger et al., 1995; Koh et al., 1995) will be determined primarily by the closing rate of open and open blocked channels as they relax into adjacent closed and closed blocked states, respectively, as shown in Model 2. At the modestly depolarized membrane potentials required for initiation of action potential discharge, the rate of open-channel block by polyamines is quite modest (Fig. $3 E$ ) and would not be expected to greatly accelerate the rate of decay of EPSCs; however, the relative occupancy of closed and closed blocked states would be transiently altered immediately after an EPSC. This is because the occupancy of these closed states reflects voltage-dependent block by polyamines of the adjacent open states. Although, because of the slow kinetics of recovery from desensitization of GluR6 (Heckmann et al., 1996; Traynelis and Wahl, 1997), we have no information on the kinetics of rebinding of Spm to closed channels, the presence of polyamines in the cytoplasm requires that closed channels will eventually relax back into the closed blocked state. One consequence of this is that our model for polyamine block shows short-term plasticity similar to that recently observed for polyamine block of both native and recombinant AMPA receptors (Rozov et al., 1998). Although our experiments were performed using GluR6, the high expression of which facilitated analysis of macroscopic GluR responses in outside-out patches, we believe that the mechanism we propose is similar for both kainate and AMPA receptors.

Simulations with Model 2 show that the peak amplitude of successive responses to Glu occurring before the reaccumulation of channels in the closed blocked state will progressively increase during train applications of agonist or presumably with repeated activation of synapses, the explanation being that after each successive release of L-Glu, fewer and fewer channels remain in the closed blocked state. A direct test of this prediction is not possible with GluR6(Q) channels, which recover slowly from desensitization. However, when rate constants are adjusted to simulate responses for GluR-D, an AMPA receptor with rapid kinetics of recovery from desensitization (Lomeli et al., 1994) that is expressed at high levels in hippocampal interneurons (Geiger et al., 1995), our model predicts facilitation for responses evoked by a train of pulses of Glu (Fig. 6). Such polyaminedependent potentiation of peak Glu responses has been recently observed for both recombinant and native AMPA receptors (Rozov et al., 1998). Together, these observations indicate that calcium-permeable AMPA and kainate receptors probably share a common mechanism of block by cytoplasmic polyamines and suggest novel roles for polyamines in short-term synaptic plasticity.

Polyamine block might also influence action potential back propagation into the dendritic tree depending on the coincidence of action potential discharge and synaptic activity. Action potentials arriving at the peak of a synaptic response will be attenuated because of the lower impedance of the dendritic membrane resulting from flux-dependent relief of polyamine block (e.g., Fig. $5 A$ ). In support of this, simulations of the activity of neocortical neurons shows that the amplitude of back-propagating action potentials can be modulated in a graded manner by alterations in background synaptic activity (Rapp et al., 1996). If, however, the synaptic response occurs when the membrane potential is already depolarized, then polyamine block will strongly attenuate this shunting effect on the action potential. The dynamic nature of this effect would be expected to vary with the history of activity at individual synapses. At sites where a low density of $\mathrm{Na}$ channels in the postsynaptic membrane decreases the safety factor for action potential initiation, inward rectifying synaptic responses resulting from polyamine block would also be expected to produce more efficient excitation. This would occur principally when action potential discharge is initiated at dendritic sites (Hausser 
et al., 1995). In view of the cell-specific expression of polyaminesensitive AMPA and kainate receptors, it will be important in future studies to elucidate whether the dynamic nature of polyamine block at glutamatergic synapses, which we model here, does contribute to the functional properties of interneurons in network activity (Buzsáki and Chrobak, 1995; Jefferys et al., 1996).

\section{REFERENCES}

Bähring R, Mayer ML (1998) An analysis of philanthotoxin block for recombinant rat GluR6(Q) glutamate receptor channels. J Physiol (Lond) 509:635-650.

Bähring R, Bowie D, Benveniste M, Mayer ML (1997) Permeation and block of rat GluR6 glutamate receptor channels by internal and external polyamines. J Physiol (Lond) 502:575-589.

Baukrowitz T, Yellen G (1996) Use-dependent blockers and exit rate of the last ion from the multi-ion pore of a $\mathrm{K}^{+}$-channel. Science 271:653-656.

Blanpied TA, Boeckman FA, Aizenman E, Johnson JW (1997) Trapping channel block of NMDA-activated responses by amantadine and memantine. J Neurophysiol 77:309-323.

Bowie D, Mayer ML (1995) Inward rectification of both AMPA and kainate subtype glutamate receptors generated by polyamine-mediated ion channel block. Neuron 15:453-462.

Bowie D, Mayer ML (1996) Dual blockade of glutamate receptors by external divalent cations and internal polyamines. Soc Neurosci Abstr 22:590.

Brooks SP, Storey KB (1992) Bound and determined: a computer program for making buffers of defined ion concentrations. Anal Biochem 201:119-126.

Burnashev N, Villarroel A, Sakmann B (1996) Dimensions and ion selectivity of recombinant AMPA and kainate receptor channels and their dependence on Q/R site residues. J Physiol (Lond) 496:165-173.

Buzsáki G, Chrobak JJ (1995) Temporal structure in spatially organized neuronal ensembles: a role for interneuronal networks. Curr Opin Neurobiol 5:504-510.

Castillo PE, Malenka RC, Nicoll RA (1997) Kainate receptors mediate a slow postsynaptic current in hippocampal CA3 neurons. Nature 388:182-186.

Chittajallu R, Vignes M, Dev KK, Barnes JM, Collingridge GL, Henley JM (1996) Regulation of glutamate release by presynaptic kainate receptors in the hippocampus. Nature 379:78-81.

Clements JD, Lester RAJ, Tong G, Jahr CE, Westbrook GL (1992) The time course of glutamate in the synaptic cleft. Science 258:1498-1501.

Colquhoun D, Hawkes AG (1977) Relaxation and fluctuations of membrane currents that flow through drug-operated channels. Proc R Soc Lond B Biol Sci 199:231-262.

Colquhoun D, Sheridan RE (1981) The modes of action of gallamine. Proc R Soc Lond B Biol Sci 211:181-203.

Donevan SD, Rogawski MA (1995) Intracellular polyamines mediate inward rectification of $\mathrm{Ca}^{2+}$-permeable $\alpha$-amino-3-hydroxy-5-methyl4-isoxazoleproprionic acid receptors. Proc Natl Acad Sci USA 92:9298-9302.

Doyle DA, Cabral JM, Pfuetzner RA, Kuo A, Gulbis JM, Cohen SL, Chait BT, MacKinnon R (1998) The structure of the potassium channel: molecular basis of $\mathrm{K}^{+}$conduction and selectivity. Science 280:69-77.

Geiger JRP, Melcher T, Koh DS, Sakmann B, Seeburg PH, Jonas P, Monyer H (1995) Relative abundance of subunit mRNAs determines gating and $\mathrm{Ca}^{2+}$ permeability of AMPA receptors in principle neurons and interneurons in rat CNS. Neuron 15:193-204.

Geiger JRP, Lübke J, Roth A, Frotscher M, Jonas P (1997) Submillisecond AMPA receptor-mediated signalling at a principal neuron-interneuron synapse. Neuron 18:1009-1023.

Hausser M, Stuart G, Racca C, Sakmann B (1995) Axonal initiation and active dendritic propagation of action potentials in substantia nigra neurons. Neuron 15:637-647.

Heckmann M, Bufler J, Franke C, Dudel J (1996) Kinetics of homomeric GluR6 glutamate receptor channels. Biophys J 71:1743-1750.

Higuchi M, Single FN, Köhler M, Sommer B, Sprengel R, Seeburg PH (1993) RNA editing of AMPA receptor subunit GluR-B: a base-paired intron-exon structure determines position and efficiency. Cell 75:1361-1370.
Hille B (1992) Ionic channels of excitable membranes. Sunderland, MA: Sinauer Associates.

Howe JR (1996) Homomeric and heteromeric ion channels formed from kainate-type subunits GluR6 and KA2 have very small, but different, unitary conductances. J Neurophysiol 76:510-519.

Isa T, Iino M, Itazawa S, Ozawa S (1995) Spermine mediates inward rectification of $\mathrm{Ca}\left({ }^{2+}\right)$-permeable AMPA receptor channels. NeuroReport 6:2045-2048.

Isa T, Itazawa S, Iino M, Tsuzuki K, Ozawa S (1996) Distribution of neurones expressing inwardly rectifying and $\mathrm{Ca}^{2+}$-permeable AMPA receptors in rat hippocampal slices. J Physiol (Lond) 491:719-733.

Jefferys JG, Traub RD, Whittington MA (1996) Neuronal networks for induced "40 Hz" rhythms. Trends Neurosci 19:202-208.

Jonas P, Burnashev N (1995) Molecular mechanisms controlling calcium entry through AMPA-type glutamate receptor channels. Neuron 15:987-990.

Jonas P, Spruston N (1994) Mechanisms shaping glutamate-mediated excitatory postsynaptic currents in the CNS. Curr Opin Neurobiol 4:366-372.

Kamboj SK, Swanson GT, Cull-Candy SG (1995) Intracellular spermine confers rectification on rat calcium-permeable AMPA and kainate receptors. J Physiol (Lond) 486:297-303.

Koh DS, Burnashev N, Jonas P (1995) Block of native $\mathrm{Ca}^{2+}$-permeable AMPA receptors in rat brain by intracellular polyamines generates double rectification. J Physiol (Lond) 486:305-312.

Kuner T, Wollmuth LP, Karlin A, Seeburg PH, Sakmann B (1996) Structure of the NMDA receptor channel M2 segment inferred from the accessibility of substituted cysteines. Neuron 17:343-352.

Kuner T, Beck C, Seeburg PH, Sakmann B (1997) Pore-lining residues of the AMPA receptor channel M2 segment. Soc Neurosci Abstr 23:925.

Lomeli H, Mosbacher J, Melcher T, Höger T, Geiger JRP, Kuner T, Monyer H, Higuchi M, Bach A, Seeburg PH (1994) Control of kinetic properties of AMPA receptor channels by nuclear RNA editing. Science 266:1709-1713.

McBain CJ, Dingledine R (1993) Heterogeneity of synaptic glutamate receptors on CA3 stratum radiatum interneurones of rat hippocampus. J Physiol (Lond) 462:373-392.

Mulle C, Sailer A, Perez-Otano I, Dickinson-Anson H, Castillo PE, Bureau I, Maron C, Gage FH, Mann JR, Bettler B, Heinemann SF (1998) Altered synaptic physiology and reduced susceptibility to kainate-induced seizures in GluR6-deficient mice. Nature 392:601-605.

Neher E (1983) The charge carried by single channel currents of rat cultured muscle cells in the presence of local anaesthetics. J Physiol (Lond) 339:663-678.

Nichols CG, Lopatin AN (1997) Inward rectifier potassium channels. Annu Rev Physiol 59:171-191.

Pegg AE (1986) Recent advances in the biochemistry of polyamines in eukaryotes. Biochem J 234:249-262.

Rapp M, Yarom Y, Segev I (1996) Modeling back propagating action potential in weakly excitable dendrites of neocortical pyramidal cells. Proc Natl Acad Sci USA 93:11985-11990.

Rodriguez-Moreno A, Herreras O, Lerma J (1997) Kainate receptors presynaptically downregulate GABAergic inhibition in the rat hippocampus. Neuron 19:893-901.

Rozov A, Zilberter Y, Wollmuth LP, Burnashev N (1998) Facilitation of currents through rat $\mathrm{Ca}^{2+}$-permeable AMPA receptor channels by activity-dependent relief from polyamine block. J Physiol (Lond) 511:361-377.

Sommer B, Köhler M, Sprengel R, Seeburg PH (1991) RNA editing in brain controls a determinant of ion flow in glutamate-gated channels. Cell 67:11-19.

Swanson GT, Feldmeyer D, Kaneda M, Cull-Candy SG (1996) Effect of RNA editing and subunit co-assembly on single-channel properties of recombinant kainate receptors. J Physiol (Lond) 492:129-142.

Swanson GT, Kamboj SK, Cull-Candy SG (1997) Single-channel properties of recombinant AMPA receptors depend on RNA editing, splice variation, and subunit composition. J Neurosci 17:58-69.

Traynelis SF, Wahl P (1997) Control of rat GluR6 glutamate receptor open probability by protein kinase A and calcineurin. J Physiol (Lond) 503:513-531.

Vignes M, Collingridge GL (1997) The synaptic activation of kainate receptors. Nature 388:179-182.

Vyklicky L, Benveniste M, Mayer ML (1990) Modulation of $N$-methylD-aspartic acid receptor desensitization by glycine in mouse cultured hippocampal neurones. J Physiol (Lond) 428:313-331. 